\title{
Efficacy of fulguration combined with imiquimod cream on condyloma acuminatum, and the effect on immune functions and serums levels of IL-2 and IL-10
}

\author{
QUAN CHEN, RIDONG YANG, AILI GAO, DAOQING ZHONG and HUILAN ZHU \\ Guangzhou Institute of Dermatology, Institute of Dermatology, Guangzhou Medical University, \\ Guangzhou, Guangdong 510095, P.R. China
}

Received February 6, 2017; Accepted March 1, 2017

DOI: $10.3892 / \mathrm{etm} .2017 .4445$

\begin{abstract}
The objective of the present study was to investigate the clinical efficacy of high-frequency fulguration combined with $5 \%$ imiquimod cream for condyloma acuminatum (CA), and the effect on $\mathrm{T}$ cell immune function and serum levels of interleukin (IL)-2 and IL-10. We enrolled 112 patients with CA between January 2014 and January 2016. Patients were randomly divided into the control group $(n=56)$ and observation group $(n=56)$. The control group received high-frequency fulguration combined with intramuscular injection of Bacillus Calmette-Guérin polysaccharide nucleic acid, and the observation group received high-frequency fulguration combined with external application of 5\% imiquimod cream. In both groups, the course of treatment lasted for 12 weeks, and the follow-up period was 6 months. Clinical efficacy was compared between the groups. The total effective rate in the observation group was higher than that in the control group $(\mathrm{p}<0.05)$, but no significant differences were identified in comparisons of effectiveness and recurrence rate between the two groups $(\mathrm{p}>0.05)$. After treatment, the levels of $\mathrm{CD}^{+}$ and $\mathrm{CD}^{+}$cells, and $\mathrm{CD} 4^{+} / \mathrm{CD}^{+}$ratio in both groups were increased compared with those before treatment $(\mathrm{p}<0.05)$, while no significant difference was identified in comparison of the levels of $\mathrm{CD}^{+}$cells in both groups before and after treatment $(\mathrm{p}>0.05)$; in both groups before and after treatment, there was no significant difference in the comparison of $\mathrm{T}$ cells $(p>0.05)$. After treatment in both groups, the serum levels of IL-2 were increased, and the levels of IL-10 were decreased compared with those before treatment; the improvement in the observation group was superior to that in the control
\end{abstract}

Correspondence to: Dr Huilan Zhu, Guangzhou Institute of Dermatology, Institute of Dermatology, Guangzhou Medical University, 56 Hengfu Road, Guangzhou, Guangdong 510095, P.R. China

E-mail: hj37w4@163.com; zhlhuilan@gmail.com

Key words: fulguration, imiquimod cream, condyloma acuminatum, T cell immune functions, IL-2, IL-10 group ( $\mathrm{p}<0.05)$. In conclusion, good efficacy can be achieved with the combined treatment of high-frequency fulguration and $5 \%$ imiquimod cream for CA, which is correlated with enhanced immune functions of $\mathrm{T}$ cells, and improvements in the serum levels of IL-2 and IL-10.

\section{Introduction}

Condyloma acuminatum (CA) is a sexually transmitted disease that manifests as epidermal wart-like hyperplasia caused by human papilloma virus (HPV). The incidence rate of CA is only secondary to gonorrhea, and CA is generally characterized by strong infectivity and high recurrence rate (1). Clinical treatment methods include chemotherapy, physiotherapy, immunotherapy and photodynamic therapy. Among them, physiotherapeutic methods, such as high-frequency fulguration and $\mathrm{CO}_{2}$ laser therapy, have various advantages such as rapid clearance of warts, high safety and low cost, although the recurrence rate of CA is relatively high $(2,3)$. Decreased immune functions of cells surrounding warts, and subclinical infection are major factors contributing to recurrence (4). Although Bacillus Calmette-Guérin polysaccharide nucleic acid (BCG-PSN) can serve as an efficient two-sided immune regulator, it is limited in clinical application because of the requirement for cold preservation and aggravated pain from intramuscular injection (5). Topical 5\% imiquimod cream is a new form of immune regulator that is convenient and safe for application (6). In this study, we aimed to analyze the clinical efficacy of high-frequency fulguration combined with $5 \%$ imiquimod cream for the treatment of $\mathrm{CA}$, and determine the effect of this treatment on the immune functions of T cells, and serum levels of interleukin (IL)-2 and IL-10.

\section{Patients and methods}

Patients. We consecutively selected 112 patients who were diagnosed with CA in Guangzhou Institute of Dermatology between January 2014 and January 2016. This study was approved by the Ethics Committee of Guangzhou Medical University. Signed written informed consents were obtained from the patients and/or guardians before the study. The inclusion criteria were as follows: i) patients who met the diagnostic 
criteria of CA, typical clinical manifestations + positive result in acetowhitening test + positive result in HPV immune colloidal gold test; ii) patients with good tolerance for treatment, complete medical history, and who signed the written informed consent. Exclusion criteria were as follows: i) patients who were in the gestation or lactation period; ii) patients with autoimmune diseases, or those who took immunosuppressors or glucocorticoid drugs within two weeks of examination; iii) patients who were allergic to BCG-PSN or imiquimod cream; and iv) patients who were complicated with other underlying diseases, such as dysfunctions of the heart, liver, lung, kidney or brain.

According to order of hospitalization, the patients were randomly divided into the observation group $(n=56)$ and control group $(n=56)$. Baseline parameters of patients in both groups were comparable (Table I).

Research methods. Patients in the control group received high-frequency fulguration and intramuscular injection of BCG-PSN. For high-frequency fulguration, a GX-III Type Series Multi-Purpose Electric Ion Operating Apparatus (Nanning Kelun New Technology Co., Ltd., Guangxi, China) was applied as follows: after standard disinfection and topical anesthesia, the metal contactor was moved from the inner part to the outer part of the skin lesion for fulguration; the range of fulguration was set as $0.5 \mathrm{~cm}$ of the diameter of warts, and the contactor could reach the upper dermis; regular anti-infection procedures were applied; after 1 week, patients received intramuscular injections (1 ml) of BCG-PSN (Disu, approved no. S19983036, 1 ml/bottle; Zhejiang Wanma Pharmaceutical Co., Ltd., Zhejiang, China), 3 times/week; the treatment course lasted for 12 weeks.

Patients in the observation group received the combination therapy of high-frequency fulguration and external application of 5\% imiquimod cream. The fulguration procedures were the same as in the control group. Imiquimod cream (Likejie, approved no. H20030129, 3 g:150 mg; Hubei Keyi Pharmaceutical Co., Ltd., Hubei, China) was applied before sleep 3 times/week, and lesions were rinsed using water the next morning; the treatment course lasted for 12 weeks.

Observational indexes. During the 6-month follow-up, we compared the clinical effective rate and recurrence rate between the two groups. The evaluation criteria of clinical effectiveness were as follows: completely cured, recovered, effective and non-effective. Completely cured was characterized by normal skin mucosa, negative result in acetowhitening test, complete remission of warts, and no recurrence in 6 months; recovered was characterized by fundamentally normal skin mucosa, positive result in acetowhitening test, $80 \%$ remission of warts, and no aggravation or recurrence in 6 months; effective referred to significant recovery in skin mucosa, positive result in acetowhitening test, 50-79\% remission of warts, and no aggravation or recurrence in 6 months; non-effective referred to no changes or aggravation in clinical symptoms and vital signs, and positive result in acetowhitening test. Recurrence referred to the emergence of newly-developed warts at the original wart site or within $2.0 \mathrm{~cm}$ area of the original wart site in 6 months, and positive result in acetowhitening test with exclusion of repeated history of infection. Total effective
Table I. Comparison of baseline parameters between the two groups.

\begin{tabular}{|c|c|c|c|c|}
\hline Groups & $\begin{array}{l}\text { Control } \\
(n=56)\end{array}$ & $\begin{array}{l}\text { Observation } \\
\quad(n=56)\end{array}$ & $\mathrm{t} / \chi^{2}$ test & P-value \\
\hline Male/female & $32 / 24$ & $35 / 21$ & 0.334 & 0.563 \\
\hline Age (years) & $41.2 \pm 6.9$ & $39.8 \pm 5.7$ & 0.252 & 0.687 \\
\hline $\begin{array}{l}\text { Disease } \\
\text { course (days) }\end{array}$ & $21.5 \pm 7.3$ & $22.6 \pm 7.8$ & 0.196 & 0.859 \\
\hline $\begin{array}{l}\text { Location of } \\
\text { skin lesion }\end{array}$ & & & 0.944 & 0.624 \\
\hline Penis & 28 & 33 & & \\
\hline Perineum & 15 & 13 & & \\
\hline Crissum & 13 & 10 & & \\
\hline Shape of wart & & & 0.207 & 0.902 \\
\hline Papulous-shaped & 15 & 13 & & \\
\hline Cauliflower-shaped & 30 & 32 & & \\
\hline Papilloma-shaped & 11 & 11 & & \\
\hline $\begin{array}{l}\text { Diameter of } \\
\text { skin lesion }(\mathrm{cm})\end{array}$ & $1.1 \pm 0.4$ & $1.2 \pm 0.5$ & 0.096 & 0.925 \\
\hline $\begin{array}{l}\text { Number of } \\
\text { skin lesion }\end{array}$ & $4.3 \pm 1.2$ & $4.6 \pm 1.5$ & 0.152 & 0.868 \\
\hline Initial onset & 48 & 47 & 0.069 & 0.792 \\
\hline Recurrence & 8 & 9 & & \\
\hline
\end{tabular}

rate $=$ (completely cured cases + recovered cases + effective cases)/total cases x $100 \%$; effective degree referred to the relative ratios of completely cured cases, recovered cases and effective cases; recurrence rate $=$ cases of recurrence/total effective cases $\mathrm{x} 100 \%$.

We compared the immune functions of $\mathrm{T}$ cells, and the serum levels of IL-2 and IL-10 of patients in both groups. A total of $6 \mathrm{ml}$ of fasting elbow venous blood was collected from patients in the morning, and the samples were centrifuged at $2,500 \mathrm{x} g$ for $20 \mathrm{~min}$. The upper serum layer was preserved at $-70^{\circ} \mathrm{C}$. The levels of IL- 2 and IL-10 were measured by enzyme-linked immunosorbent assay (ELISA) (KeyGen, Nanjing, China) according to the manufacturer's instructions. Reagents were purchased from Beyotime Institute of Biotechnology (Jiangsu, China). Measurement was repeated three times, and data were averaged. The cells were placed in lymphocyte separation medium, followed by density gradient centrifugation for the isolation of cells. FACSCaliber flow cytometry (BD Biosciences, Franklin Lakes, NJ, USA) was applied for the detection of $\mathrm{CD}^{+}, \mathrm{CD}^{+}$and $\mathrm{CD}^{+}$cells, and the percentage of $\mathrm{CD}^{+} / \mathrm{CD}^{+}$.

Statistical analysis. SPSS 20.0 statistical software (SPSS, Inc., Chicago, IL, USA) was applied for statistical analysis. Numerical data are presented as mean \pm standard deviation (SD), independent sample t-test was applied for intergroup comparisons, and paired t-test was applied for intragroup comparisons. Categorical data are presented as cases or 
Table II. Clinical effective rate and recurrence rate (cases, \%).

\begin{tabular}{lcccccc}
\hline Groups & Completely cured & Recovered & Effective & Non-effective & Effective rate & Recurrence rate \\
\hline Control (n=56) & 25 & 7 & 8 & 16 & $40(71.4)$ & $4(10.0)$ \\
Observation (n=56) & 32 & 10 & 7 & 7 & $49(87.5)$ & $3(6.1)$ \\
Z/ $\chi^{2}$ test & & -1.858 & & 4.432 & - \\
P-value & & 0.063 & & 0.035 & 0.696 \\
\hline
\end{tabular}

Table III. Percentage of T cell (\%).

\begin{tabular}{|c|c|c|c|c|c|c|c|c|}
\hline \multirow[b]{2}{*}{ Groups } & \multicolumn{2}{|c|}{$\mathrm{CD}^{+}$} & \multicolumn{2}{|c|}{$\mathrm{CD}^{+}$} & \multicolumn{2}{|c|}{$\mathrm{CD}^{+}$} & \multicolumn{2}{|c|}{$\mathrm{CD}^{+} / \mathrm{CD}^{+}{ }^{+}$} \\
\hline & $\begin{array}{c}\text { Before } \\
\text { treatment }\end{array}$ & $\begin{array}{c}\text { After } \\
\text { treatment }\end{array}$ & $\begin{array}{c}\text { Before } \\
\text { treatment }\end{array}$ & $\begin{array}{c}\text { After } \\
\text { treatment }\end{array}$ & $\begin{array}{c}\text { Before } \\
\text { treatment }\end{array}$ & $\begin{array}{c}\text { After } \\
\text { treatment }\end{array}$ & $\begin{array}{c}\text { Before } \\
\text { treatment }\end{array}$ & $\begin{array}{c}\text { After } \\
\text { treatment }\end{array}$ \\
\hline Control & $35.9 \pm 6.2$ & $38.6 \pm 6.6^{\mathrm{a}}$ & $29.8 \pm 5.4$ & $33.6 \pm 6.2^{\mathrm{a}}$ & $32.4 \pm 6.2$ & $32.8 \pm 6.4$ & $92.5 \pm 8.2$ & $105.5 \pm 11.2^{\mathrm{a}}$ \\
\hline Observation & $34.3 \pm 6.4$ & $38.5 \pm 6.7^{\mathrm{a}}$ & $28.7 \pm 5.3$ & $33.3 \pm 6.4^{\mathrm{a}}$ & $31.6 \pm 6.3$ & $32.4 \pm 6.6$ & $93.1 \pm 8.3$ & $104.7 \pm 12.3^{a}$ \\
\hline t-test & 0.152 & 0.096 & 0.232 & 0.078 & 0.312 & 0.102 & 0.352 & 0.152 \\
\hline P-value & 0.896 & 0.935 & 0.852 & 0.924 & 0.789 & 0.936 & 0.724 & 0.968 \\
\hline
\end{tabular}

${ }^{\mathrm{a}} \mathrm{p}<0.05$, comparison of the levels before and after treatment.

ratio (\%), and Chi-square test or Fisher's exact probability test was applied for intergroup comparisons. Rank-sum test was applied for the comparison of ranked data. $\mathrm{P}<0.05$ was considered to indicate a statistically significant difference.

\section{Results}

Clinical effective rate and recurrence rate. The total effective rate in the observation group was higher than that in the control group $(\mathrm{p}<0.05)$, but no significant differences were identified in comparisons of the effective and recurrence rate between the two groups ( $\mathrm{p}>0.05$; Table II).

Immune functions of $T$ cells. After treatment, the levels of $\mathrm{CD}^{+}$and $\mathrm{CD}^{+}$cells, and the $\mathrm{CD}^{+} / \mathrm{CD}^{+}$ratio in both groups were increased compared with the levels before treatment $(\mathrm{p}<0.05)$. There was no significant difference in the levels of $\mathrm{CD}^{+}$cells in either group before and after treatment $(p>0.05)$. There was no significant difference in the comparison of $\mathrm{T}$ cells before and after treatment between the groups ( $\mathrm{p}>0.05$; Table III).

Serum levels of $I L-2$ and $I L-10$. In both groups, the serum levels of IL-2 were increased and the levels of IL-10 were decreased after treatment, compared with the levels before treatment. This improvement was superior in the observation group compared with the control group ( $\mathrm{p}<0.05$; Table IV).

\section{Discussion}

CA is characterized by a relatively long latency period, few obvious manifestations in the early period, and a wide range of contagions. Photodynamic treatment of $\mathrm{CA}$ in the urethral orifice of male patients can achieve good efficacy,
Table IV. Serum levels of IL-2 and IL-10 $(\mu \mathrm{g} / \mathrm{l})$.

\begin{tabular}{lccccc}
\hline & \multicolumn{2}{c}{ IL-2 } & & \multicolumn{2}{c}{ IL-10 } \\
\cline { 2 - 3 } \cline { 5 - 6 } Groups & $\begin{array}{c}\text { Before } \\
\text { treatment }\end{array}$ & $\begin{array}{c}\text { After } \\
\text { treatment }\end{array}$ & & $\begin{array}{c}\text { Before } \\
\text { treatment }\end{array}$ & $\begin{array}{c}\text { After } \\
\text { treatment }\end{array}$ \\
\hline Control & $112.3 \pm 45.5$ & $154.8 \pm 52.3^{\mathrm{a}}$ & & $65.3 \pm 23.2$ & $58.7 \pm 21.2^{\mathrm{a}}$ \\
Observation & $105.6 \pm 46.8$ & $198.3 \pm 57.9^{\mathrm{a}}$ & & $66.8 \pm 25.4$ & $51.2 \pm 22.7^{\mathrm{a}}$ \\
t-test & 0.213 & 9.524 & & 0.154 & 7.523 \\
P-value & 0.865 & 0.001 & & 0.968 & 0.001 \\
\hline
\end{tabular}

${ }^{\mathrm{a}} \mathrm{p}<0.05$, comparison of the levels before and after treatment. IL, interleukin.

but cannot be promoted in clinical practice because of high medical costs (7). Therefore, high-frequency fulguration combined with immune enhancing therapy has currently become the major treatment method. In this study, we employed high-frequency fulguration combined with immune enhancing therapy, although high-frequency fulguration cannot effectively eliminate residual HPV surrounding warts. These HPVs were primarily distributed within the range of 1.0-2.0 $\mathrm{cm}$ away from the center of warts, which resulted in HPV being the main pathogen $(8)$. Previous studies $(9,10)$ have confirmed that imiquimod cream, with no antiviral effect, can promote peripheral monocytes and keratinocyte to express and secrete multiple cytokines, such as interferon- $\gamma$ (INF- $\gamma$ ), IL-2 and IL-12, thus enhancing the immune functions of B lymphocytes and T lymphocytes. Regarding the Th1 cellular immunity in HPV infection, imiquimod cream can thoroughly eliminate the viral infection, resulting in clinical cure. BCG-PSN is also an efficient two-sided immune 
regulator. In this study, we found that the total effective rate in the observation group was higher than that in the control group, but no significant differences were identified in the comparisons of the effective degree and recurrence rate between the two groups. A previous study (11) reported that compared with healthy subjects, the levels of $\mathrm{CD}^{+}$and $\mathrm{CD}^{+}$cells in peripheral blood of patients with CA are lower, the levels of $\mathrm{CD}^{+}$cells are elevated, and the $\mathrm{CD}^{+} / \mathrm{CD}^{+}$ratio is significantly decreased. Compared with the levels before treatment, the levels of $\mathrm{CD}^{+}$and $\mathrm{CD}^{+}$cells, and the percentage of $\mathrm{CD}^{+} / \mathrm{CD}^{+}$were increased after treatment, but no changes were observed in the levels of $\mathrm{CD}^{+}$cells. In addition, there were no significant differences in the comparison of $\mathrm{T}$ cells before and after treatment between the two groups. These results demonstrated the equivalent efficiency of the drugs for enhancing the immune response to cytotoxicity. In both groups, the serum levels of IL-2 were increased after treatment compared with those before treatment, and the levels of IL-10 were decreased. The improvement in patients of the observation group was superior to that of the control group. This suggested that imiquimod cream may excel in enhancing the functions of cytokines. IL-2, also known as a $\mathrm{T}$ cell growth factor, is generally produced by activated $\mathrm{CD}^{+}$and $\mathrm{CD}^{+} \mathrm{T}$ cells, and has a wide range of biological activities $(12,13)$. However, IL-10, a multifunctional negative regulator, is mainly involved in autoimmune diseases, infectious diseases, tumors and transplantation immunity $(14,15)$.

Imiquimod cream is an artificially synthesized non-nucleoside heterocyclic amine drug. It is characterized by relatively minor local responses compared with BCG-PSN, such as local erythema and mild erosion. Patients can frequently tolerate these symptoms, which are important factors affecting the efficacy of treatment (16). However, single administration of immunopotentiators may result in delays of treatment because the onset time of imiquimod cream is $4-12$ weeks, which is insufficient for treatment (17). In conclusion, good clinical efficacy for the treatment of CA can be achieved via the combination of high-frequency fulguration and 5\% imiquimod cream, and is correlated with enhanced immune functions of T cells, and improvement in the serum levels of IL-2 and IL-10. Therefore, this treatment method is worthy of being promoted in clinical practice.

\section{Acknowledgements}

This study was done with support from the Medical Scientific Research Foundation of Guangdong Province (A2015331), Guangzhou Medical and Health Science and Technology Project (20141A011072) and Guangzhou Medical and Health Science and Technology Project (20171A011287).

\section{References}

1. Yanofsky VR, Patel RV and Goldenberg G: Genital warts: a comprehensive review. J Clin Aesthet Dermatol 5: 25-36, 2012.

2. Akhavizadegan $\mathrm{H}$ : Electrocautery resection, shaving with a scalpel, and podophyllin: a combination therapy for giant condyloma acuminatum. World J Mens Health 33: 39-41, 2015.

3. Omi T and Numano K: The role of the $\mathrm{CO}_{2}$ laser and fractional $\mathrm{CO}_{2}$ laser in dermatology. Laser Ther 23: 49-60, 2014.

4. Léonard B, Kridelka F, Delbecque K, Goffin F, Demoulin S, Doyen J and Delvenne P: A clinical and pathological overview of vulvar condyloma acuminatum, intraepithelial neoplasia, and squamous cell carcinoma. BioMed Res Int 2014: 480573, 2014.

5. Thappa DM and Chiramel MJ: Evolving role of immunotherapy in the treatment of refractory warts. Indian Dermatol Online J 7: 364-370, 2016.

6. Kim JM, Lee HJ, Kim SH, Kim HS, Ko HC, Kim BS, Kim MB and Song M: Efficacy of 5\% imiquimod cream on vulvar intraepithelial neoplasia in Korea: pilot study. Ann Dermatol 27: 66-70, 2015.

7. Wan MT and Lin JY: Current evidence and applications of photodynamic therapy in dermatology. Clin Cosmet Investig Dermatol 7: 145-163, 2014.

8. Maniar KP, Ronnett BM, Vang R and Yemelyanova A: Coexisting high-grade vulvar intraepithelial neoplasia (VIN) and condyloma acuminatum: independent lesions due to different HPV types occurring in immunocompromised patients. Am J Surg Pathol 37: 53-60, 2013.

9. Lucs AV, DeVoti JA, Hatam L, Afzal A, Abramson AL, Steinberg BM and Bonagura VR: Immune dysregulation in patients persistently infected with human Papillomaviruses 6 and 11. J Clin Med 4: 375-388, 2015.

10. Li W, Xin H, Ge L, Song H and Cao W: Induction of vitiligo after imiquimod treatment of condylomata acuminata. BMC Infect Dis 14: 329, 2014.

11. Reusser NM, Downing C, Guidry J and Tyring SK: HPV carcinomas in immunocompromised patients. J Clin Med 4: 260-281, 2015.

12. Sinha S, Relhan V and Garg VK: Immunomodulators in warts: unexplored or ineffective? Indian J Dermatol 60: 118-129, 2015.

13. Cao Y, Zhao J, Yang Z, Cai Z, Zhang B, Zhou Y, Shen GX, Chen X, Li S and Huang B: CD4 ${ }^{+} \mathrm{FOXP}^{+}$regulatory $\mathrm{T}$ cell depletion by low-dose cyclophosphamide prevents recurrence in patients with large condylomata acuminata after laser therapy. Clin Immunol 136: 21-29, 2010.

14. Chathra N, Sukumar D, Bhat RM, Kishore BN, Martis J, Kamath G, Srinath MK and Monteiro R: A comparative study of $10 \% \mathrm{KOH}$ solution and 5\% imiquimod cream for the treatment of Molluscum contagiosum in the pediatric age group. Indian Dermatol Online J 6: 75-80, 2015.

15. Sung JH, Ahn EJ, Oh HK and Park SH: Association of immune status with recurrent anal condylomata in human immunodeficiency virus-positive patients. J Korean Soc Coloproctol 28: 294-298, 2012.

16. Jeon HC, Choi M, Paik SH, Ahn CH, Park HS and Cho KH: Treatment of keratoacanthoma with 5\% imiquimod cream and review of the previous report. Ann Dermatol 23: 357-361, 2011.

17. Alessi SS, Sanches JA, Oliveira WR, Messina MC, Pimentel ER and Festa Neto C: Treatment of cutaneous tumors with topical 5\% imiquimod cream. Clinics (São Paulo) 64: 961-966, 2009. 